\title{
Measurement of Hepatocyte Growth Factor, Interleukin 6 and Tumor necrosis factor $\alpha$ in Acute Myocardial Infarction
}

\author{
Asadallah Keshmiri ${ }^{1}$, Ali Reza Derakhshan ${ }^{2}$, Afsoon Fazlinejad ${ }^{3}$, Reza Farid-Hosseini ${ }^{4}$ \\ ${ }^{1}$ Department of Emergency Medicine, School of Medicine, Birjand University of Medical Sciences, Birjand, Iran. asad.keshmiri@yahoo.com \\ ${ }^{2}$ Department of Persian Medicine, School of Persian and Complementary Medicine, Mashhad University of Medical Sciences, Mashhad. Iran \\ derakhshanar@mums.ac.ir \\ ${ }^{3}$ Echocardiography Research fellow ,Mayo clinic 13400 E Shea Blvd,Arizona. Fazlinezhad.afsoon@mayo.edu \\ ${ }^{4}$ Allergy Research Center, School of Medicine, Mashhad University of Medical Sciences, Mashhad, Iran. rfarid@gmail.com
}

Corresponding Author: Afsoon Fazlinejad

Echocardiography Research fellow, Mayo clinic

Address: 13400 E Shea Blvd,Arizona.

E-mail: Fazlinezhad.afsoon@mayo.edu

Cite this article as: Keshmiri A, Derakhshan AR, Fazlinejad A, et al. Measurement of Hepatocyte Growth Factor, Interleukin 6 and Tumor necrosis factor $\alpha$ in Acute Myocardial Infarction. Nepalese Heart Journal 2019; Vol 16(1), 33-37

Received date: 11 th October 2018

Accepted date: 30th March 2019

Abstract

Background: Early mortality rate due to acute myocardial infarction (AMI) is approximately $30 \%$, and half of these deaths occur before reaching a hospital. The prevention and early detection play a key role in reducing mortality in AMI. Hepatocyte Growth Factor (HGF), Interleukin 6 (IL-6), and Tumor Necrosis Factor $\alpha$ (TNF- $\alpha$ ) are most recent prognostic biomarkers for AMI. The present study was aimed to evaluate the level of these cytokines in AMI.

Methods: In this case control study, 39 patients with AMI were compared with 30 healthy subjects. Age, sex and other possible confounding factors were matched. AMI diagnosis was confirmed by typical symptoms, electrocardiogram changes and serum concentration of troponin I and creatine kinase-MB. The levels of TNF- $\alpha$, IL- 6 an HGF at baseline and 3 and 7 days later were measured using ELISA method.

Results: Levels of IL-6, TNF- $\alpha$ and HGF increased over time after AMI with ST-segment elevation in study group. The baseline IL-6 levels in AMI group were significantly higher than control group $(\mathrm{P}<0.05)$.

Conclusions: The results of this study suggest that baseline levels of IL-6 as well as serial changes of serum IL-6, TNF- $\alpha$ and HGF concentrations can be used as potential diagnostic biomarkers in AMI.

Keywords: acute myocardial infarction, hepatocyte growth factor, interleukin 6 , TNF- $\alpha$

DOI: https://doi.org/10.3126/njh.v16i1.23896

\section{Introduction}

One of the major causes of mortality and morbidity worldwide, especially in many developed countries is coronary artery disease (CAD). ${ }^{1}$ In some countries CAD is the cause of nearly half $(48 \%)$ of the deaths, and as a result loss of the productivity of life. If no serious action is taken, the number of years of productivity life lost to CAD will increase to $64 \%$ for Brazil and even more dramatically to $95 \%$ for India, by 2030 as compared to $2000 .^{2}$ According to the World Health Organization, it is predicted that by 2030, 23.6 million deaths per year will be due to cardiovascular diseases. ${ }^{1}$ A large proportion of CADs occur because of the atherosclerosis. Although the etiology of atherosclerosis is complex and poorly known, there is growing evidence that inflammation plays a central role in developing atherosclerotic lesion, which is in turn widely considered to be related to an inflammatory process. ${ }^{3}$
It has been proven that both behavioral risk factors (such as tobacco use, unhealthy diet, physical inactivity, and harmful use of alcohol) and metabolic risk factors (such as diabetes, hypertension, high blood lipids, overweight and obesity) possess a crucial role in the etiology of atherosclerosis. ${ }^{5}$ The fragility of the atherosclerotic plaque is associated with the inflammation and plays a significant role in destroying of the fibrous cap, which is the main pathophysiological event for the progression of acute coronary syndromes (ACS) such as unstable angina (UA) and acute myocardial infarction (AMI) ${ }^{6}$ Recent studies showed that some inflammatory cytokines (IL-6, TNF- $\alpha$ and IL-10) were predictors for cardiovascular outcome. ${ }^{7,8}$ During the first 48 hours of an ACS, IL-6 has been proved a great predictor of a major adverse cardiovascular event over the first month after the initial coronary event and the first year. ${ }^{9}$ It has been observed

@Nepalese Heart Journal. Nepalese Heart Journal retains copyright and work is simultaneously licensed under Creative Commons Attribution License CC - BY 4.0 that allows others to share the work with an acknowledgement of the work's authorship and initial publication in this journal. 
that circulating IL-6 concentrations is positively associated with the risk of CAD. Also, high IL-6 levels during acute coronary syndromes (ACS) may be associated with worse long-term prognosis. ${ }^{10}$ Some studies have indicated that IL-6 and CRP are powerful predictors of risky coronary events in patients with UA as well as independent risk factors for future MI. In addition, levels of TNF- $\alpha$ were associated with high risk of recurrent coronary events and it is also able to be potential markers for prediction of cardiovascular events. ${ }^{11-13}$

Hepatocyte growth factor (HGF) is a cytokine with multipotent actions. ${ }^{14}$ It has multiple activities in various tissues during the development of diverse diseases and regulates cell growth, cell motility, and morphogenesis of various types of cells. HGF is also a sensitive biomarker for early diagnosis of acute myocardial infarction that between the known biomarkers, it rises the earliest and very promptly returns to normal values. ${ }^{15}$, ${ }^{16}$ Some study showed that HGF levels on admission in patients with AMI were higher than control values and peaked on 7 th day. ${ }^{17,18}$ In addition, it has been demonstrated that serum HGF concentrations in early stage might reflect the extent of myocardial damage in AMI patients. HGF was increased within three hours after onset of chest pain in most of AMI patients. ${ }^{16}$ Therefore, HGF is useful as a prognostic indicator in patients with $\mathrm{AMI}$ and reflects the clinical course of disease.

The aim of this study, is finding cytokine levels and serial changes of HGF, IL-6, and TNF- $\alpha$ in the patients with ST elevation AMI.

\section{Methods and materials}

We conducted a case control hospital-based study on 39 patients with AMI who were referred to the Ghaem academic hospital in Mashhad (northeast of Iran) and 30 healthy control subjects. AMI was diagnosed based on typical chest pain lasting $30 \mathrm{~min}$, with ST-T segment elevation $>0.2 \mathrm{mV}$ in 2 or more contiguous leads on a standard 12-lead electrocardiogram and an increase in Troponin and Creatine Kinase MB activity that was at least twice the upper limit of normal. Healthy control subjects $(\mathrm{n}=$ 30) were recruited from among subjects who were referred to for an annual checkup or pre-employment examination as they were assumed not to have CAD and gave no history of cardiovascular symptoms. Also, patients who had history of antiplatelet and statin medication were excluded from control group.

Case and controls subjects were age, and sex matched Clinical signs and laboratory results (Troponin I and Creatine Kinase MB) of patients with AMI were documented.

The levels of these cytokines were evaluated at three points in the patients with AMI. In addition, the possible relationship between these three factors with echocardiographic findings and Killip class were evaluated. Killip classification is defined based on the Killip's article in $1967 .^{19}$

\section{The Laboratory Measurement of Cytokines and bio- chemical parameters}

Venous blood samples were taken from patients immediately before the administration of heparin at the time of admission, and 3 and 7 days later. Serums were separated from blood samples by centrifugation, and were stored at $-70^{\circ} \mathrm{C}$. ELISA cytokines have been used for HGF, IL-6, and TNF-a measurement.

Fasted blood samples $(20 \mathrm{ml})$ were collected into plain Vacutainer ${ }^{\mathrm{TM}}$ tubes, for cytokines and growth factor measurements, lipid profile and those for measurement of fasting blood glucose was taken into Vacutainer ${ }^{\mathrm{TM}}$ tubes containing fluoride-oxalate. ${ }^{20}$
Total cholesterol (TC), low density lipoprotein cholesterol (LDLC), high density lipoprotein cholesterol (HDLC), Triglyceride (TG) and fasting blood sugar (FBS) were measured using routine techniques using a Cobas auto-analyser system (ABX Diagnostics, Montpellier, France). ${ }^{20}$

The results of the $\mathrm{FBS}<110 \mathrm{mg} / \mathrm{dL}$ were interpreted normal values, FBS between 110 and $126 \mathrm{mg} / \mathrm{dL}$ were considered as impaired fasting glucose (IFG), and FBS $>126 \mathrm{mg} / \mathrm{dL}$ were considered as Diabetes Mellitus, according to the American Diabetic Association criteria. ${ }^{20}$

\section{Statistical analysis:}

The Statistical Package for Social Sciences (SPSS version 16) was used for data analysis. The Kolmogorov-Smirnov test was used to assess normality. Descriptive statistics (frequency, mean, and standard deviation) were determined for all variables. Values are reported as mean \pm SD for normally distributed variables (or Median and IQR for not normal distribute variable). Baseline demographics and clinical characteristics were compared among groups using t-student test, chi-square test, and/or Fisher exact test as appropriate. A P-value $<0.05$ was regarded as statistically significant.

\section{Ethical Issue:}

The study was conducted in accordance with the principles of Declaration of Helsinki 1996 version and Good Clinical Practice standards. The study protocol, informed-consent form, and the other study related documents were reviewed and approved by Human Research Ethics Committee of Mashhad University of Medical Sciences.

\section{Results}

The main age of case group subjects was $55.74 \pm 13.08$ and in the control group was $64.9 \pm 10.5$ with no significant difference between groups in sex, smoking habit, opium addiction, hypertension, hyperlipidemia, diabetes mellitus, and stroke history $(\mathrm{P}>0.05)$ (table1).

In case group $41 \%$ ( 16 subjects) had history of unstable angina whereas in control group nobody had this history and there was a significant difference between groups $(\mathrm{P}<0.001)$ (table1).

In the biochemical components of blood analysis there were no significant difference between groups in FBS, LDLC, HDLC, TC, TG, BUN, Creatinine, Hemoglobin, and Hematocrit $(\mathrm{P}>0.05)$ (table1).

According to the electrocardiograph analysis most of patients in case group (more than 77\%) had inferior wall ST elevation myocardial infarction (MI) followed by anterior wall ST elevation MI (table2).

In cytokine assay between groups at baseline, IL-6 in case group was significantly higher than control group $(\mathrm{P}=0.001)$ but differences in HGF and TNF-a are not significant $(\mathrm{P}>0.05)$ (table 1). In addition, serial cytokine assay in case group showed that serum levels of IL-6, TNF-a and HGF have increased significantly over time $(\mathrm{P}<0.05)($ table 3$)$. 
Table 1- basic characteristics of case and control subjects

\begin{tabular}{|c|c|c|c|c|}
\hline group Variable & & Case $\mathrm{N}=39$ & Control $\mathrm{N}=30$ & $\mathrm{P}$ value \\
\hline Age & & $55.74 \pm 13.08$ & $64.9 \pm 10.5$ & 0.477 \\
\hline \multirow[t]{2}{*}{ Sex } & Male & $26(66.7)$ & $18(60)$ & 0.567 \\
\hline & Female & $13(33.3)$ & $12(40)$ & \\
\hline \multirow[t]{2}{*}{ Smoking } & Present & $12(30)$ & $10(33.3)$ & 0.874 \\
\hline & Absent & $27(70)$ & $20(66.7)$ & \\
\hline \multirow[t]{2}{*}{ Addiction history } & Present & $7(17.9)$ & $8(26.6)$ & 0.611 \\
\hline & Absent & $32(82.1)$ & $22(73.4)$ & \\
\hline \multirow[t]{2}{*}{ Hypertension } & Present & 19(48.7) & $8(26.6)$ & 0.840 \\
\hline & Absent & $20(51.3)$ & $22(73.4)$ & \\
\hline \multirow[t]{2}{*}{ Diabetes Mellitus } & Present & $4(10.25)$ & $3(10)$ & 0.743 \\
\hline & Absent & $35(89.75)$ & $27(90)$ & \\
\hline \multirow[t]{2}{*}{ Hyperlipidemia } & Present & $9(23)$ & $10(33.3)$ & 0.344 \\
\hline & Absent & $30(77)$ & $20(66.7)$ & \\
\hline \multirow[t]{2}{*}{ Stroke History } & Present & $2(5.1)$ & $1(3.33)$ & 0.953 \\
\hline & Absent & $37(94.9)$ & $29(96.6)$ & \\
\hline \multirow[t]{2}{*}{ Unstable angina history } & Present & $16(41)$ & $0(0.0)$ & $<0.001$ \\
\hline & Absent & $23(59)$ & $30(100)$ & \\
\hline \multirow[t]{2}{*}{ Killip classification } & I & $32(82)$ & - & - \\
\hline & II & $7(18)$ & - & \\
\hline \multirow[t]{4}{*}{ Ejection fraction } & $<30 \%$ & $7(18)$ & - & - \\
\hline & $30-40 \%$ & $7(18)$ & - & \\
\hline & $40-50 \%$ & $22(57)$ & - & \\
\hline & $>50 \%$ & $3(7)$ & - & \\
\hline End diastolic & Grade I & $28(72)$ & - & - \\
\hline Left ventricular function & Grade II & $11(28)$ & - & \\
\hline \multicolumn{2}{|l|}{$\mathrm{FBS}(\mathrm{mg} / \mathrm{dl})$} & $120.12 \pm 25.66$ & $110 \pm 24.1$ & 0.345 \\
\hline \multicolumn{2}{|l|}{$\mathrm{TC}(\mathrm{mg} / \mathrm{dl})$} & $162.88 \pm 38.70$ & $165 \pm 40.67$ & 0.061 \\
\hline \multicolumn{2}{|l|}{ LDL-C (mg/dl) } & $96.77 \pm 35.130$ & $100 \pm 37$ & 0.084 \\
\hline \multicolumn{2}{|l|}{ HDL-C (mg/dl) } & $41.55 \pm 8.25$ & $43 \pm 9.54$ & 0.093 \\
\hline \multicolumn{2}{|l|}{$\mathrm{TG}(\mathrm{mg} / \mathrm{dl})$} & $152.59 \pm 84.674$ & $160 \pm 87.47$ & 0.099 \\
\hline \multicolumn{2}{|l|}{ BUN } & $27.50 \pm 8.88$ & $25 \pm 7.98$ & 0.455 \\
\hline \multicolumn{2}{|l|}{ Creatinine } & $0.994 \pm 0.288$ & $0.85 \pm 0.3$ & 0.833 \\
\hline \multicolumn{2}{|l|}{ Hemoglobin } & $12.63 \pm 1.79$ & $13.5 \pm 1.94$ & 0.433 \\
\hline \multicolumn{2}{|l|}{ Hematocrit } & $39.194 \pm 4.67$ & $42 \pm 4.5$ & 0.532 \\
\hline \multirow[t]{3}{*}{ Base Line } & HGF & $1913 \pm 2101$ & $1294 \pm 562$ & 0.1 \\
\hline & TNF- $\alpha$ & $39.59 \pm 119$ & $17 \pm 7$ & 0.27 \\
\hline & IL-6 & $132.26 \pm 86.41$ & $52 \pm 13$ & 0.001 \\
\hline
\end{tabular}

${ }^{\text {a }}$ FBS: Fasting blood sugar

b TC: total cholesterol

${ }^{c}$ LDL-C: Low density lipoprotein- cholesterol

${ }^{\mathrm{d}}$ HDL-C: High density lipoprotein- cholesterol

${ }^{\mathrm{e}}$ TG: triglyceride 
Table 2- electrocardiogram abnormal findings

\begin{tabular}{|l|l|l|}
\hline \multirow{2}{*}{ Lead } & Abnormal Findings & No.(\%) \\
\hline \multirow{2}{*}{ Anterior leads } & Present & $14(36)$ \\
\cline { 2 - 3 } & Absent & $25(64)$ \\
\hline \multirow{2}{*}{ Inferior leads } & Present & $18(46)$ \\
\cline { 2 - 3 } & Absent & $21(54)$ \\
\hline \multirow{2}{*}{ Right lead } & Present & $30(77)$ \\
\cline { 2 - 3 } & Absent & $9(23)$ \\
\hline \multirow{2}{*}{ Posterior lead } & Present & $8(20)$ \\
\cline { 2 - 3 } & Absent & $31(80)$ \\
\hline
\end{tabular}

Table 3- Cytokine assay in Case group during hospital stay ${ }^{\mathrm{a}}$

\begin{tabular}{|l|l|l|l|l|l|}
\hline & Base line & 3rd days after AMI & 7th days after AMI & $\mathrm{P}_{0}^{\mathrm{b}}$ & $\mathrm{P}_{1}^{\mathrm{c}}$ \\
\hline $\mathrm{HGF}_{(\mathrm{pg} / \mathrm{mL})}$ & $1360(1225-1601)$ & $1810(1310-2516)$ & $1913(1565-4367)$ & 0.006 & 0.006 \\
\hline TNF-a $_{(\mathrm{pg} / \mathrm{mL})}$ & $3.2(2.9-3.6)$ & $3.3(3-3.7)$ & $3.3(3.1-3.8)$ & 0.012 & 0.008 \\
\hline $\mathrm{IL}_{(\mathrm{pg} / \mathrm{mL})}$ & $102(86-142)$ & $167(145-408)$ & $203(162-590)$ & $<0.001$ & $<0.001$ \\
\hline
\end{tabular}

a Data shown as Median (Interquartile range)

${ }^{\mathrm{b}} \mathrm{P}_{0}$ is $\mathrm{P}$ value of comparing between base line via $3^{\text {rd }}$ days after AMI.

${ }^{c} P_{1}$ is $P$ value of comparing between base line via $7^{\text {th }}$ days after AMI.

${ }^{d} \mathrm{P}_{2}$ is $\mathrm{P}$ value of comparing between $3^{\text {rd }}$ days via $7^{\text {th }}$ days after $\mathrm{AMI}$.

\section{Discussion}

The main findings of this study are that (1) IL-6 increases in early phase after AMI and that (2) serial elevation in serum levels of IL-6, TNF- $\alpha$ and HGF occurs after AMI.

It had been proved previously that thrombus formation induces the HGF circulating and it is increasing after AMI. ${ }^{21}$ Also HGF serum level is higher in angina pectoris and old myocardial infarction..$^{22}$ Soeki et al. showed that HGF levels in patients with AMI were higher than control values at the time of admission. Also, levels of HGF on day 7 after AMI were higher than baseline levels ${ }^{18}$. In the present study, although difference between baseline HGF in case group and control group was not significant, HGF levels of case group in day 3 was higher than baseline and in day 7 was higher than baseline and 3rd day. Serial increased levels of HGF over time, have not been reported previously.

Cytokine IL-6 is the major procoagulant that is secreted by numerous cells such as monocytes, lymphocytes, fibroblasts, endothelial cells and smooth muscle. ${ }^{23}$ Puhakka et al. found that IL-6 has increased immediately and transiently after AMI. ${ }^{24}$ In a case-control study with 1179 surviving AMI cases and 1528 healthy controls, it was proved that in men, MI risk was higher with increasing IL-6 levels. ${ }^{25}$

Increased IL-6 in the first 48 hours after ACS is associated with prognosis of future cardiovascular events. ${ }^{23}$ In addition, IL-6 in the patients with refractory unstable angina are higher than those with stable angina. ${ }^{26} \mathrm{~A}$ study that was conducted on 38 patients with stroke showed that IL-6 levels are increased in stroke with mechanisms of atherosclerosis plaque rapture. ${ }^{27} \mathrm{We}$ found same result in our study; IL-6 was higher in case group than controls at the admission time. It also increased serially on 3rd day and 7 th day after admission.

TNF- $\alpha$ can be produced by many cell types such as macrophage cells, lymphoid cells, mast cells, endothelial cells, cardiac myocytes and adipose tissue. It is known as a regulator of inflammatory cells, and as a pyrogenic agent. TNF-a is involved in almost all aspects of the inflammatory process of atherosclerosis. ${ }^{28}$ High levels of TNF-a in the patients after AMI is an independent risk factor in cardiovascular events occuring again. ${ }^{28}$ It was shown before that TNF- $\alpha$ increase significantly on admission and 24 hours post admission in AMI patients comparing to control group. ${ }^{29}$ Although high levels of TNF-a on admission time were not confirmed in our study, serial increase of this cytokine over time was observed.

\section{Conclusion}

We have reported increased levels of IL-6, TNF-a and HGF during AMI with ST-segment elevation patients. At the admission time, the IL-6 levels were significantly higher than the control group. So, besides the clinical signs and symptoms of AMI, measuring IL-6 may be helpful for diagnosis of this disease. It seems that further studies are needed to determine sensitivity and specificity in larger number of patients.

\section{Conflict of Interest Statement}

The authors indicate no potential conflicts of interest.

\section{Ethical approval}

All procedures performed in studies involving human participants were in accordance with the ethical standards of the institutional and/or national research committee and with the 1964 Helsinki declaration and its later amendments or comparable ethical standards.

\section{Funding}

This study was supported by Mashhad University of Medical Sciences.

\section{References}

1. Chen C, Lei W, Chen W, et al. Serum TGF-beta1 and 
SMAD3 levels are closely associated with coronary artery disease. BMC cardiovascular disorders. 2014;14:18.

https://doi.org/10.1186/1471-2261-14-18

2. Go AS, Mozaffarian D, Roger VL, et al. Heart Disease and Stroke Statistics--2014 Update: A Report From the American Heart Association. Circulation. 2013.

3. Biswas S, Ghoshal PK, Mandal N. Synergistic effect of anti and pro-inflammatory cytokine genes and their promoter polymorphism with ST-elevation of myocardial infarction. Gene. 2014;544(2):145-51.

https://doi.org/10.1016/j.gene.2014.04.065

4. Anderson DR, Poterucha JT, Mikuls TR, et al. IL-6 and its receptors in coronary artery disease and acute myocardial infarction. Cytokine. 2013;62(3):395-400.

https://doi.org/10.1016/j.cyto.2013.03.020

5. Mendis S, Puska P, Norrving B, Organization WH, Federation WH, Organization WS. Global Atlas on Cardiovascular Disease Prevention and Control: World Health Organization in collaboration with the World Heart Federation and the World Stroke Organization; 2011.

6. Rajappa M, Sen S, Sharma A. Role of pro-/anti-inflammatory cytokines and their correlation with established risk factors in South Indians with coronary artery disease. Angiology. 2009;60(4):419-26.

https://doi.org/10.1177/0003319708321101

7. Antonicelli R, Olivieri F, Bonafe M, et al. The interleukin-6 $-174 \mathrm{G}>\mathrm{C}$ promoter polymorphism is associated with a higher risk of death after an acute coronary syndrome in male elderly patients. International journal of cardiology. 2005;103(3):266-71.

https://doi.org/10.1016/j.ijcard.2004.08.064

8. Antonicelli R, Olivieri F, Cavallone L, et al. Tumor necrosis factor-alpha gene $-308 \mathrm{G}>\mathrm{A}$ polymorphism is associated with ST-elevation myocardial infarction and with high plasma levels of biochemical ischemia markers. Coronary artery disease. 2005;16(8):489-93.

https://doi.org/10.1097/00019501-200512000-00006

9. Ohtsuka T, Hamada M, Inoue $\mathrm{K}$, et al. Relation of circulating interleukin-6 to left ventricular remodeling in patients with reperfused anterior myocardial infarction. Clin Cardiol. 2004;27(7):417-20.

https://doi.org/10.1002/clc.4960270712

10. Kanikowska D, Pyda M, Korybalska K, et al. Age-related limitations of interleukin-6 in predicting early mortality in acute ST-elevation myocardial infarction. Immunity \& ageing : I \& A. 2014;11(1):23.

https://doi.org/10.1186/s12979-014-0023-7

11. Tousoulis D, Antoniades C, Koumallos N, et al. Proinflammatory cytokines in acute coronary syndromes: from bench to bedside. Cytokine \& growth factor reviews. 2006;17(4):225-33.

https://doi.org/10.1016/j.cytogfr.2006.04.003

12. Pudil R, Pidrman V, Krejsek J, et al. Cytokines and adhesion molecules in the course of acute myocardial infarction. Clin Chim Acta. 1999;280(1-2):127-34. https://doi.org/10.1016/S0009-8981(98)00179-X

13. Martins TB, Anderson JL, Muhlestein JB, et al. Risk factor analysis of plasma cytokines in patients with coronary artery disease by a multiplexed fluorescent immunoassay. American journal of clinical pathology. 2006;125(6):906-13. https://doi.org/10.1309/Q3E6KF0QD3U3YL6T

14. Jin H, Wyss JM, Yang R, et al. The therapeutic potential of hepatocyte growth factor for myocardial infarction and heart failure. Current pharmaceutical design. 2004;10(20):252533. https://doi.org/10.2174/1381612043383863

15. Konopka A, Janas J, Piotrowski W, et al. Hepatocyte growth factor - the earliest marker of myocardial injury in STsegment elevation myocardial infarction. Kardiologia polska. 2013;71(8):827-31.

https://doi.org/10.5603/KP.2013.0194

16. Matsumori A, Furukawa Y, Hashimoto T, et al. Increased circulating hepatocyte growth factor in the early stage of acute myocardial infarction. Biochemical and biophysical research communications. 1996;221(2):391-5. https://doi.org/10.1006/bbrc.1996.0606

17. Zhu Y, Hojo Y, Ikeda U, et al. Production of hepatocyte growth factor during acute myocardial infarction. Heart (British Cardiac Society). 2000;83(4):450-5. https://doi.org/10.1136/heart.83.4.450

18. Soeki T, Tamura Y, Shinohara H, et al. Serial changes in serum VEGF and HGF in patients with acute myocardial infarction. Cardiology. 2000;93(3):168-74.

https://doi.org/10.1159/000007022

19. Killip T, 3rd, Kimball JT. Treatment of myocardial infarction in a coronary care unit. A two year experience with 250 patients. Am J Cardiol. 1967;20(4):457-64.

https://doi.org/10.1016/0002-9149(67)90023-9

20. Kazemi-Bajestani SM, Ghayour-Mobarhan M, Ebrahimi $\mathrm{M}$, et al. C-reactive protein associated with coronary artery disease in Iranian patients with angiographically defined coronary artery disease. Clin Lab. 2007;53(1-2):49-56.

https://doi.org/10.1016/S1567-5688(08)70910-3

21. Brown LF, Yeo KT, Berse B, et al. Expression of vascular permeability factor (vascular endothelial growth factor) by epidermal keratinocytes during wound healing. J Exp Med. 1992;176(5):1375-9. https://doi.org/10.1084/jem.176.5.1375

22. Soeki T, Tamura Y, Shinohara H, et al. Role of circulating vascular endothelial growth factor and hepatocyte growth factor in patients with coronary artery disease. Heart Vessels. 2000;15(3):105-11. https://doi.org/10.1007/PL00007263

23. Mouco OM, Nicolau JC, Souza Tda R, et al. [Inflammatory markers of atherosclerotic plaque stabilization after acute coronary event--temporal trends]. Arq Bras Cardiol. 2006;87(1):28-36. https://doi.org/10.1590/S0066-782X2006001400005

24. Puhakka M, Magga J, Hietakorpi S, et al. Interleukin-6 and tumor necrosis factor alpha in relation to myocardial infarct size and collagen formation. J Card Fail. 2003;9(4):325-32. https://doi.org/10.1054/jcaf.2003.38

25. Bennet AM, Prince JA, Fei GZ, et al. Interleukin-6 serum levels and genotypes influence the risk for myocardial infarction. Atherosclerosis. 2003;171(2):359-67. https://doi.org/10.1016/j.atherosclerosis.2003.08.029

26. Hojo Y, Ikeda U, Takahashi M, et al. Increased levels of monocyte-related cytokines in patients with unstable angina. Atherosclerosis. 2002;161(2):403-8.

https://doi.org/10.1016/S0021-9150(01)00636-0

27. Kim HM, Shin HY, Jeong HJ, et al. Reduced IL-2 but elevated IL-4, IL-6, and IgE serum levels in patients with cerebral infarction during the acute stage. J Mol Neurosci. 2000;14(3):191-6. https://doi.org/10.1385/JMN:14:3:191

28. Tuttolomondo A, Di Raimondo D, Pecoraro R, et al. Atherosclerosis as an inflammatory disease. Curr Pharm Des. 2012;18(28):4266-88. https://doi.org/10.2174/138161212802481237, https://doi.org/10.2174/138161212802481246

29. Fahim MR, Halim SM, Kamel I. Tumor necrosis factor alpha in patients with acute myocardial infarction. The Egyptian journal of immunology / Egyptian Association of Immunologists. 2004;11(1):31-7. 